\title{
The Secrets of Writing a Truly Useful Executive Summary
}

\author{
COMMUNICATION CORNER NO. 31
}

\author{
by Philip Yaffe
}

Editor's Introduction

Each "Communication Corner" essay is self-contained; however, they build on each other. For best results, before reading this essay and doing the exercise, go to the first essay "How an Ugly Duckling Became a Swan," then read each succeeding essay.

The purpose of an executive summary is not to summarize, but to direct the reader's interest. The wider the intended audience, the wider will be their range of specific interests. But however diverse the readership, they want the document to clearly direct them to what they must read, leaving any additional text they may wish to also peruse to their own judgement. 


\title{
The Secrets of Writing a Truly Useful Executive Summary
}

\author{
by Philip Yaffe
}

In virtually all walks of life-business, education, politics, research, etc.-documents of more than a few of pages consist of the body and an executive summary. Unfortunately, most writers treat the executive summary as an afterthought rather than a forethought.

"It's in the name, isn't it?" Indeed, it is. The term "summary" suggests that the body should be written first, and then summarized. However, to be truly useful, the summary should be written first (at least in rough) and the body afterwards.

Why? Because the purpose of the executive summary is not to summarize, but to direct.

Most people to whom executive summaries are addressed often have neither the time nor the desire to read the body of the document in its entirety. First and foremost, they need a short text that clearly relates all the key information in one place, and then provides all the details, if really required.

But isn't this precisely why the body should be written first, then summarized?

No. When writing the body first, there is a strong tendency to put in virtually all the information available. Because there are no clear criteria for determining what is truly useful and what isn't, the writer almost invariably puts in too much. Writing the summary first helps establish inclusion and exclusion criteria, so that extraneous information is less likely to clutter up and obscure what the reader really needs to know.

Writing the summary first also automatically reduces the length of the document. Most writers will claim after the first draft, they go back and remove all extraneous information. However once a piece of information has been included, it is psychologically very difficult to remove it.

"After all, I must have had a good reason for putting it in. Besides, it is interesting and/or amusing, so I think I will keep it."

Interesting and amusing are not valid criteria. If information isn't useful to the reader, it has no reason to be there. Wouldn't it be better not to include it in the first place, rather than later agonizing over cutting it out? 
To repeat, the purpose of the executive summary is not to summarize, but to direct. Treating the executive summary as a road sign rather than a dead end provides numerous advantageous for both the writer and the reader.

\section{Advantages For the Writer}

A summary that directs rather than summarizes helps the writer:

- Fully understand the information he or she is trying to communicate.

- Establish criteria for including, and more importantly, for excluding information.

- Organize the information in the most useful way possible.

\section{Advantages For the Reader}

A summary that directs rather than summarizes helps the reader:

- Get a clear overview of the information contained in the body.

- Determine which sections and subsections of the body they may find of particular importance.

- Decide whether they even need to read the body at all.

Different potential readers have different interests. For example, in a corporate report, the financial director will want a quick overview of what the document is all about, then probably specific information concerning its possible impact on the company's finances. Likewise, the director of public affairs will want a quick overview of what the document is all about, then probably specific information concerning the possible impact on relations with customers, shareholders, and the general public.

The president, of course, will want to know something about everything, but that still doesn't mean he or she must read everything. The person sitting at the apex of the pyramid will probably appreciate a summary that directs rather than summarizes more than anyone else,

The wider the intended audience, the wider will be their range of specific interests. But however diverse the recipients, they share a single common desire. They want the document to clearly direct them to what they must read, leaving any additional text they may wish to also peruse to their own judgement.

To achieve its purpose, an executive summary should be written like the lead of a newspaper article. In journalese, the "lead" is the first few sentences or paragraphs that pick out and highlight the key information to follow. Because it condenses all the key information into a 
minimum of words at the beginning, the lead allows the reader to decide if they want to go any further or devote their time and attention to something else.

In general, people who start reading a news article seldom finish it. This does not represent failure, but success. As every journalist knows, if people had to read an entire article to discover whether or not it was worth reading in the first place, they wouldn't read anything at all.

An executive summary should serve the same purpose. It should allow people to decide for themselves what they need and want to read, rather than trying to force them to read everything. For an insight into how journalists produce their clear, concise, informative leads, refer to Communication Corner No. 3 "How to Improve Your Writing by Standing On Your Head."

To underscore the executive summary's true nature and importance, perhaps the term should be dropped and replaced by something more appropriate, such as "executive briefing, "executive focus," "executive roadmap," etc.

Whatever it is called, to be truly useful this crucial part of a document should always be written first, never as an afterthought.

\section{About the Author}

Philip Yaffe was born in Boston, Massachusetts, in 1942 and grew up in Los Angeles, where he graduated from the University of California with a degree in mathematics and physics. In his senior year, he was also editor-in-chief of the Daily Bruin, UCLA's daily student newspaper. He has more than 40 years of experience in journalism and international marketing communication. At various points in his career, he has been a teacher of journalism, a reporter/feature writer with The Wall Street Journal, an account executive with a major international press relations agency, European marketing communication director with two major international companies, and a founding partner of a specialized marketing communication agency in Brussels, Belgium, where he has lived since 1974. He is the author of more than 30 books, which can be found easily in Amazon Kindle.

DOI: $10.1145 / 3427769$ 